\title{
$\mathrm{KIn}_{0.33}{ }^{\mathrm{III}} \mathrm{Te}_{0.67}{ }^{\mathrm{VI}} \mathrm{Te}_{2}{ }^{\mathrm{IV}} \mathrm{O}_{7}: \quad$ Zirconolite-like $\quad$ Mixed- Valent Metal Oxide with a 3D Framework
}

Dong Woo Lee ${ }^{1}$, Tae-Hyeong Kim ${ }^{1}$, Jeongmook Lee ${ }^{1,2}$, Junghwan Park ${ }^{1,3}$, Jong-Yun Kim ${ }^{1,2}$ Kang Min $\mathrm{Ok}^{4, *}$, and Sang Ho Lim ${ }^{1,2, *}$

${ }^{1}$ Nuclear Chemistry Research Team, Korea Atomic Energy Research Institute, Daejeon 34057, Republic of Korea

${ }^{2}$ Department of Radiochemistry \& Nuclear Nonproliferation, University of Science and Technology, Daejeon 34113, Republic of Korea

${ }^{3}$ Korea Advanced Institute of Science and Technology, Daejeon 34141, Republic of Korea ${ }^{4}$ Department of Chemistry, Sogang University, Seoul 04107, Republic of Korea Corresponding author: Sang Ho Lim (slim@kaeri.re.kr), Kang Min Ok (kmok@sogang.ac.kr) 
Table of Contents

\begin{tabular}{|c|c|c|}
\hline Section & Title & Page \\
\hline Figure $\mathrm{S} 1$. & $\begin{array}{l}\text { Ball and stick representation of } \mathrm{CsIn}_{0.33}{ }^{\mathrm{III}} \mathrm{Te}_{1.67}{ }^{\mathrm{VI}} \mathrm{O}_{6} \text { and } \\
\mathrm{KIn}_{0.33}{ }^{\mathrm{III}} \mathrm{Te}_{0.67}{ }^{\mathrm{VI}} \mathrm{Te}_{2}{ }^{\mathrm{IV}} \mathrm{O}_{7} \text { in the } a b \text { plane. }\end{array}$ & S3 \\
\hline S1 & Experimental & S3 \\
\hline Figure S2 & $\begin{array}{l}\text { Experimental and calculated powder X-ray diffraction patterns for } \\
\mathrm{KIn}_{0.33}{ }^{\mathrm{III}} \mathrm{Te}_{0.67}{ }^{\mathrm{VI}} \mathrm{Te}_{2}{ }^{\mathrm{IV}} \mathrm{O}_{7}\end{array}$ & S6 \\
\hline Table S1 & $\begin{array}{l}\text { Structural information, atomic coordinates and equivalent isotropic } \\
\text { displacement parameters, selected bond distances, and bond angles } \\
\text { of } \mathrm{KIn}_{0.33}{ }^{\mathrm{III}} \mathrm{Te}_{0.67}{ }^{\mathrm{VI}} \mathrm{Te}_{2}{ }^{\mathrm{IV}} \mathrm{O}_{7}\end{array}$ & S6 \\
\hline Figure S3 & $\begin{array}{l}\text { Thermogravimetric/Differential Scanning Calorimeter analysis } \\
\text { diagram and powder } \mathrm{X} \text {-ray diffraction patterns at different } \\
\text { temperatures for } \mathrm{KIn}_{0.33}{ }^{\mathrm{III}} \mathrm{Te}_{0.67}{ }^{\mathrm{VI}} \mathrm{Te}_{2}{ }^{\mathrm{IV}} \mathrm{O}_{7}\end{array}$ & S8 \\
\hline Figure S4 & IR spectrum for $\mathrm{KIn}_{0.33}{ }^{\mathrm{III}} \mathrm{Te}_{0.67}{ }^{\mathrm{VI}} \mathrm{Te}_{2}{ }^{\mathrm{IV}} \mathrm{O}_{7}$ & S9 \\
\hline Figure S5 & $\begin{array}{l}\text { Powder X-ray diffraction patterns of the product of the structure } \\
\text { transformation of } \mathrm{KIn}_{0.33}{ }^{\mathrm{III}} \mathrm{Te}_{0.67}{ }^{\mathrm{VI}} \mathrm{Te}_{2}{ }^{\mathrm{IV}} \mathrm{O}_{7}\end{array}$ & S9 \\
\hline
\end{tabular}


Figure S1. Ball and stick representation of CsInn.33 ${ }^{\mathrm{III}} \mathrm{Te}_{1.67}{ }^{\mathrm{VI}} \mathrm{O}_{6}$ and $\mathrm{KIn}_{0.33}{ }^{\mathrm{III}} \mathrm{Te}_{0.67}{ }^{\mathrm{VI}} \mathrm{Te}_{2}{ }^{\mathrm{IV}} \mathrm{O}_{7}$ in the $a b$ plane.
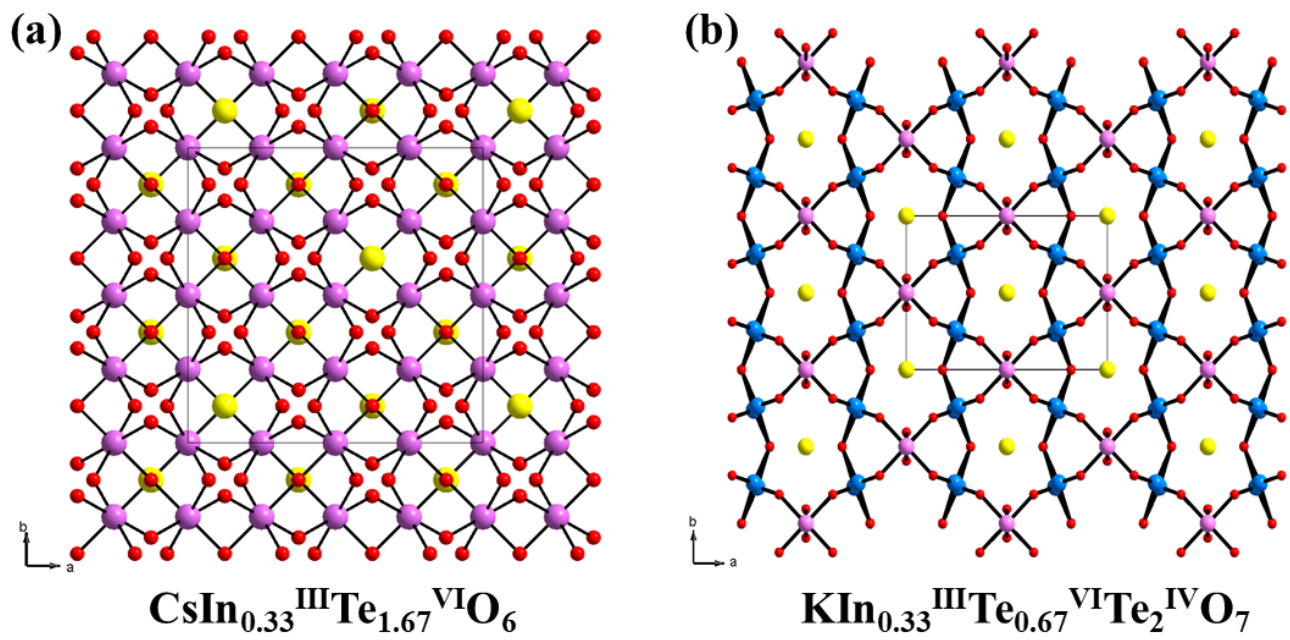

\section{S1. Experimental}

Reagents. $\mathrm{K}_{2} \mathrm{CO}_{3}$ (Alfa Aesar, 99.997\%), $\mathrm{In}\left(\mathrm{NO}_{3}\right)_{3} \cdot x \mathrm{H}_{2} \mathrm{O}$ (Alfa Aesar, 99.99\%), and $\mathrm{TeO}_{2}$ (Sigma-Aldrich, 99\%) were used as received.

Synthesis. The single crystal and pure polycrystalline phase of $\mathrm{KIn}_{0.33} \mathrm{Te}_{0.67} \mathrm{Te}_{2} \mathrm{O}_{7}$ were prepared via hydrothermal reaction by combining $\mathrm{K}_{2} \mathrm{CO}_{3}\left(0.207 \mathrm{~g}, 1.50 \times 10^{-3} \mathrm{~mol}\right)$, $\mathrm{In}\left(\mathrm{NO}_{3}\right)_{2} \cdot x \mathrm{H}_{2} \mathrm{O}\left(0.150 \mathrm{~g}, 0.50 \times 10^{-3} \mathrm{~mol}\right), \mathrm{TeO}_{2}\left(0.479 \mathrm{~g}, 3.00 \times 10^{-3} \mathrm{~mol}\right)$, and distilled water (1 mL). The mixture was loaded into a $23 \mathrm{~mL}$ Teflon-lined stainless steel autoclave. The autoclave was subsequently sealed and heated to $230{ }^{\circ} \mathrm{C}$ for 4 days before being cooled to room temperature at a rate of $6{ }^{\circ} \mathrm{Ch}^{-1}$. After cooling, the autoclave was opened, and the product was recovered by filtration, washed with water, and then dried at $100{ }^{\circ} \mathrm{C}$ overnight. Yellow plate shaped crystals were isolated in phase-pure form in $63 \%$ yield based on $\mathrm{TeO}_{2}$. The powder $\mathrm{X}$ ray diffraction $(\mathrm{XRD})$ pattern of the ground sample was in good agreement with the calculated data from the single-crystal model (see the Table S1). 


\section{Single-crystal X-ray diffraction}

A yellow plate crystal of $\mathrm{KIn}_{0.33} \mathrm{Te}_{0.67} \mathrm{Te}_{2} \mathrm{O}_{7}$ with dimensions of $0.012 \mathrm{~mm} \times 0.042 \mathrm{~mm} \times 0.013$ mm was used for structural determination. Data were collected on a Bruker PHOTON II X-ray diffractometer at $223 \mathrm{~K}$ using graphite-monochromated Mo $\mathrm{K} \alpha$ radiation. The data were integrated using the SAINT program (ver. 8.27B), ${ }^{1}$ and the intensities were corrected for Lorentz, polarization, air absorption, and absorption effects attributable to the variation in the path length through the detector faceplate. A semi-empirical absorption correction was made on the hemisphere of data using the SADABS program. ${ }^{2}$ The structure was solved by direct methods using SHELXS-13 and refined using SHELXL-13. ${ }^{3}$ Structural information, atomic coordinates and equivalent isotropic displacement parameters, selected bond distances, and bond angles of the reported material is shown in the Table S1.

\section{Powder X-ray diffraction}

Powder XRD was used to confirm the phase purity of the synthesized materials. The powder XRD data were collected on a Bruker D8 Advance X-ray diffractometer using $\mathrm{Cu} \mathrm{K} \alpha$ radiation operated at $40 \mathrm{kV}$ and $40 \mathrm{~mA}$ at room temperature. The polycrystalline samples were mounted on sample holders and scanned in the $2 \theta$ range of $10-70^{\circ}$ at a step size of $0.02^{\circ}$ and step time of $0.1 \mathrm{~s}$.

\section{Thermogravimetric/Differential Scanning Calorimeter analysis}

Thermogravimetric/Differential Scanning Calorimeter analysis (TGA/DSC) was performed on a Scinco STA N-1500 thermogravimetric analyzer. The sample was contained within an alumina crucible and heated at a rate of $10{ }^{\circ} \mathrm{C} \mathrm{min}-1$ from 30 to $1000{ }^{\circ} \mathrm{C}$ under flowing argon. 


\section{Infrared spectroscopy}

The infrared spectrum was measured on a Thermo Fisher Scientific Nicolet is50 FTIR spectrometer in the $400-4000 \mathrm{~cm}^{-1}$ range, with the well ground sample intimately contacted by a diamond as an attenuated total reflectance crystal.

\section{Inductively coupled plasma optical emission spectroscopy}

The compositions of the compounds were determined by inductively coupled plasma optical emission spectroscopy using a Horiba Jobin Yvon Activa-M spectrometer. Inductively coupled plasma analysis of $\mathrm{KIn}_{0.33} \mathrm{Te}_{2.67} \mathrm{O}_{7}$ indicated a $\mathrm{K} / \mathrm{In} / \mathrm{Te}$ ratio of 1.00:0.31:2.75.

\section{Structural transformation experiment}

To perform the structural transformation reaction, approximately $50 \mathrm{mg}$ of polycrystalline $\mathrm{KIn}_{0.33} \mathrm{Te}_{0.67} \mathrm{Te}_{2} \mathrm{O}_{7}$ was stirred in $10 \mathrm{~mL}$ of distilled water at $230{ }^{\circ} \mathrm{C}$ for 1 day. Subsequently, the product was isolated by filtration, thoroughly washed with excess water, and dried overnight at room temperature in air. 
Figure S2. Experimental and calculated powder X-ray diffraction patterns for $\mathrm{KIn}_{0.33}{ }^{\mathrm{III}} \mathrm{Te}_{0.67}{ }^{\mathrm{VI}} \mathrm{Te}_{2}{ }^{\mathrm{IV}} \mathrm{O}_{7}$

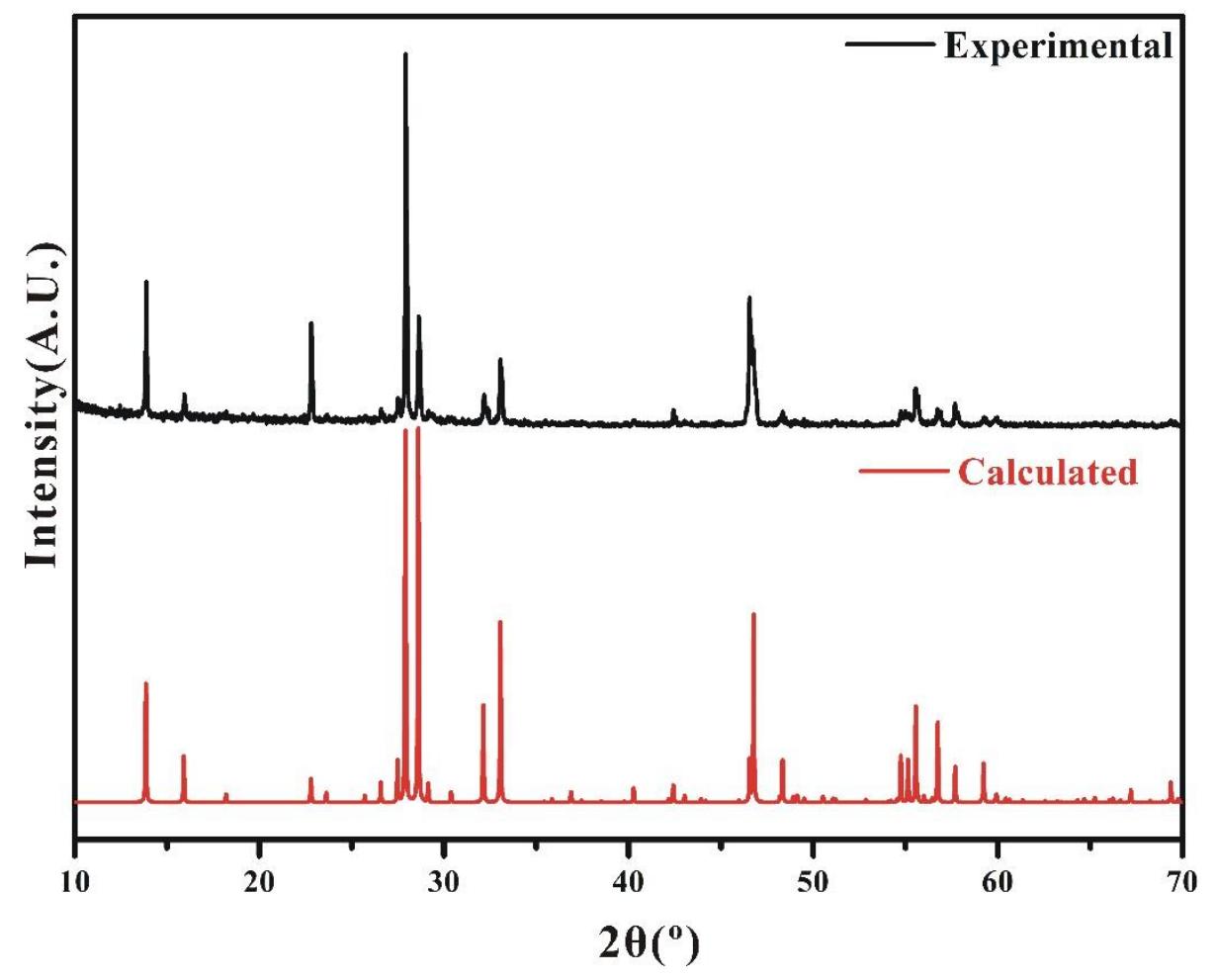

Table S1. Structural information, atomic coordinates and equivalent isotropic displacement parameters, selected bond distances, and bond angles of $\mathrm{KIn}_{0.33}{ }^{\mathrm{III}} \mathrm{Te}_{0.67}{ }^{\mathrm{VI}} \mathrm{Te}_{2}{ }^{\mathrm{IV}} \mathrm{O}_{7}$

Structural information for $\mathrm{KIn}_{0.33}{ }^{\mathrm{III}} \mathrm{Te}_{0.67}{ }^{\mathrm{VI}} \mathrm{Te}_{2}{ }^{\mathrm{IV}} \mathbf{O}_{7}$.

$\begin{array}{cc}\text { Empirical formula } & \mathrm{KIn}_{0.33} \mathrm{Te}_{2.67} \mathrm{O}_{7} \\ \text { Crystal color } & \text { Yellow } \\ \text { Crystal size }\left(\mathrm{mm}^{3}\right) & 0.121 \times 0.042 \times 0.013 \\ \text { Formula weight } & 529.64 \\ \text { Crystal system } & \text { Orthorhombic } \\ \text { Space group } & \text { Cmcm (No. 63) } \\ \mathrm{Z} & 4 \\ a(\AA) & 11.1274(10) \\ b & 7.7935(9) \\ c(\AA) & 7.5229(9)\end{array}$




\begin{tabular}{cc}
$V\left(\AA^{3}\right)$ & $652.40(12)$ \\
Temperature $(\mathrm{K})$ & $223(2)$ \\
$\rho_{\text {calcd }}\left(\mathrm{g} \cdot \mathrm{cm}^{-3}\right)$ & 5.392 \\
$\mu\left(\mathrm{mm}^{-1}\right)$ & 13.641 \\
$R(F)^{a}$ & 0.0364 \\
$R_{w}\left(F_{o}^{2}\right)^{b}$ & 0.1027 \\
\hline
\end{tabular}

${ }^{\mathrm{a}} R(F)=\Sigma|| \mathrm{F}_{\mathrm{o}}|-| \mathrm{F}_{\mathrm{c}}|| \Sigma\left|\mathrm{F}_{\mathrm{o}}\right| \cdot{ }^{\mathrm{b}} R_{w}\left(\mathrm{~F}^{2}{ }_{\mathrm{o}}\right)=\left[\Sigma w\left(\mathrm{~F}_{\mathrm{o}}^{2}-\mathrm{F}_{\mathrm{c}}^{2}\right)^{2} / \Sigma w\left(\mathrm{~F}_{\mathrm{o}}^{2}\right)^{2}\right]^{1 / 2}$.

Atomic coordinates and equivalent isotropic displacement parameters $\left(\AA^{2}\right)$ for $\mathrm{KIn}_{0.33}{ }^{\mathrm{III}} \mathrm{Te}_{0.67}{ }^{\mathrm{VI}} \mathrm{Te}_{2}{ }^{\mathrm{IV}} \mathrm{O}_{7}$.

\begin{tabular}{cccccc} 
& $x$ & $y$ & $z$ & $U_{\mathrm{eq}}{ }^{a}$ & Occupancy \\
$\mathrm{Te}(1)$ & $0.24114(6)$ & $0.26264(9)$ & 0.25 & $0.0192(3)$ & 1.0 \\
$\mathrm{Te}(2) / \mathrm{In}(1)$ & 0 & 0.5 & 0 & $0.0159(3)$ & $0.67 / 0.33$ \\
$\mathrm{~K}(1)$ & 0 & 0 & 0 & $0.0309(10)$ & 1 \\
$\mathrm{O}(1)$ & $0.1333(5)$ & $0.3117(6)$ & $0.0608(7)$ & $0.0260(11)$ & 1.0 \\
$\mathrm{O}(2)$ & 0 & $0.593(2)$ & 0.25 & $0.064(4)$ & 1.0 \\
$\mathrm{O}(3)$ & $0.3199(10)$ & $0.4975(12)$ & 0.25 & $0.058(3)$ & 1.0 \\
\hline${ }^{a} U_{\text {eq }}$ is defined as one-third of the trace of the orthogonalized $\mathrm{U}_{\mathrm{ij}}$ tensor, * Wyckoff position & \\
\hline
\end{tabular}

Selected bond distances $(\AA)$ and angles $\left({ }^{\circ}\right)$ for $\mathrm{KIn}_{0.33}{ }^{\mathrm{III}} \mathrm{Te}_{0.67}{ }^{\mathrm{VI}} \mathrm{Te}_{2}{ }^{\mathrm{IV}} \mathbf{O}_{7}$.

\begin{tabular}{llll}
\hline $\mathrm{Te}(1)-\mathrm{O}(1) \times 2$ & $1.901(5)$ & $\mathrm{O}(1)-\mathrm{Te}(1)-\mathrm{O}(1)$ & $97.0(3)$ \\
$\mathrm{Te}(1)-\mathrm{O}(3)$ & $2.029(8)$ & $\mathrm{O}(1)-\mathrm{Te}(1)-\mathrm{O}(3) \times 2$ & $95.2(3)$ \\
$\mathrm{Te}(1)-\mathrm{O}(3)$ & $2.175(11)$ & $\mathrm{O}(1)-\mathrm{Te}(1)-\mathrm{O}(3) \times 2$ & $89.7(2)$ \\
$\mathrm{Te}(2) / \mathrm{In}(1)-\mathrm{O}(1) \times 4$ & $\mathrm{O}(3)-\mathrm{Te}(1)-\mathrm{O}(3)$ & $172.6(2)$ \\
$\mathrm{Te}(2) / \mathrm{In}(1)-\mathrm{O}(2) \times 2$ & $2.136(5)$ & $\mathrm{O}(1)-\mathrm{Te}(2) / \mathrm{In}(1)-\mathrm{O}(1) \times 2$ & $88.0(3)$ \\
& $2.016(6)$ & $\mathrm{O}(1)-\mathrm{Te}(2) / \mathrm{In}(1)-\mathrm{O}(1) \times 2$ & $92.0(3)$ \\
& & $\mathrm{O}(1)-\mathrm{Te}(2) / \mathrm{In}(1)-\mathrm{O}(1) \times 2$ & 180 \\
& & $\mathrm{O}(2)-\mathrm{Te}(2) / \mathrm{In}(1)-\mathrm{O}(1) \times 4$ & $92.7(3)$ \\
& & $\mathrm{O}(2)-\mathrm{Te}(2) / \mathrm{In}(1)-\mathrm{O}(1) \times 2$ & $87.3(3)$ \\
\hline
\end{tabular}


Figure 3. Thermogravimetric/Differential Scanning Calorimeter analysis diagram and powder $\mathrm{X}$-ray diffraction patterns at different temperatures for $\mathrm{KIn}_{0.33}{ }^{\mathrm{III}} \mathrm{Te}_{0.67}{ }^{\mathrm{VI}} \mathrm{Te}_{2}{ }^{\mathrm{IV}} \mathrm{O}_{7}$
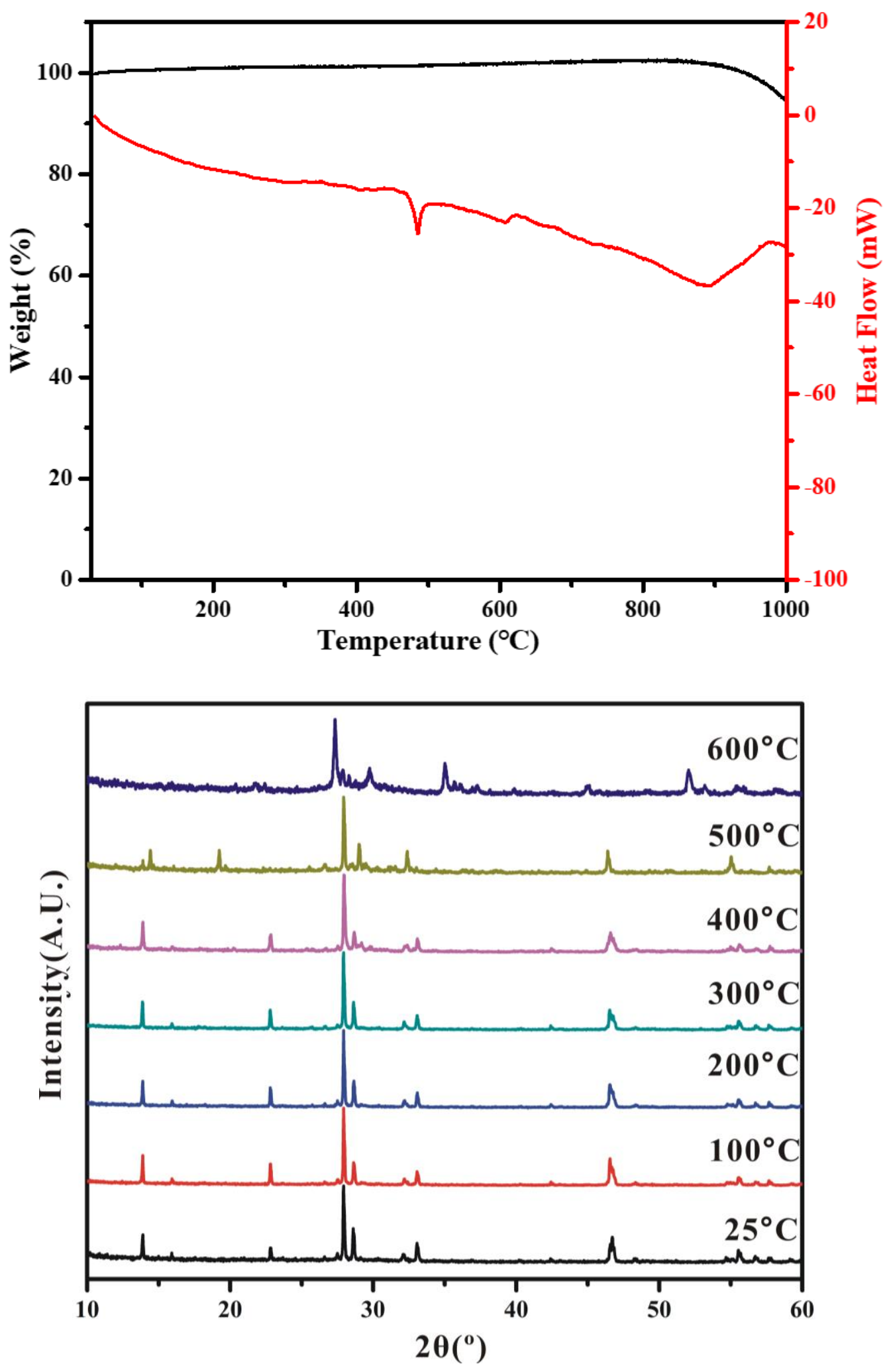
Figure S4. IR spectrum for KIn0.33 ${ }^{\mathrm{III}} \mathrm{Te}_{0.67}{ }^{\mathrm{VI}} \mathrm{Te}_{2}{ }^{\mathrm{IV}} \mathrm{O}_{7}$

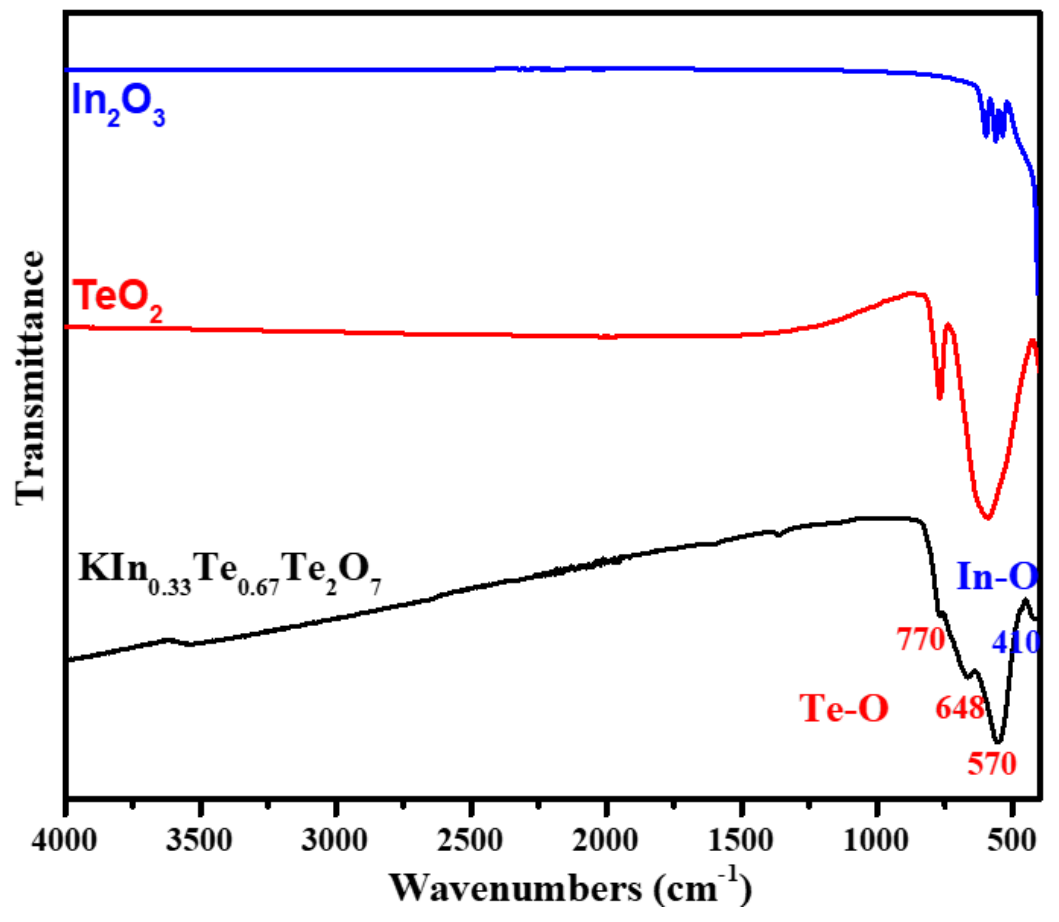

Figure S5. Powder X-ray diffraction patterns of the product of the structure transformation of $\mathrm{KIn}_{0.33}{ }^{\mathrm{III}} \mathrm{Te}_{0.67}{ }^{\mathrm{VI}} \mathrm{Te}_{2}{ }^{\mathrm{IV}} \mathrm{O}_{7}$

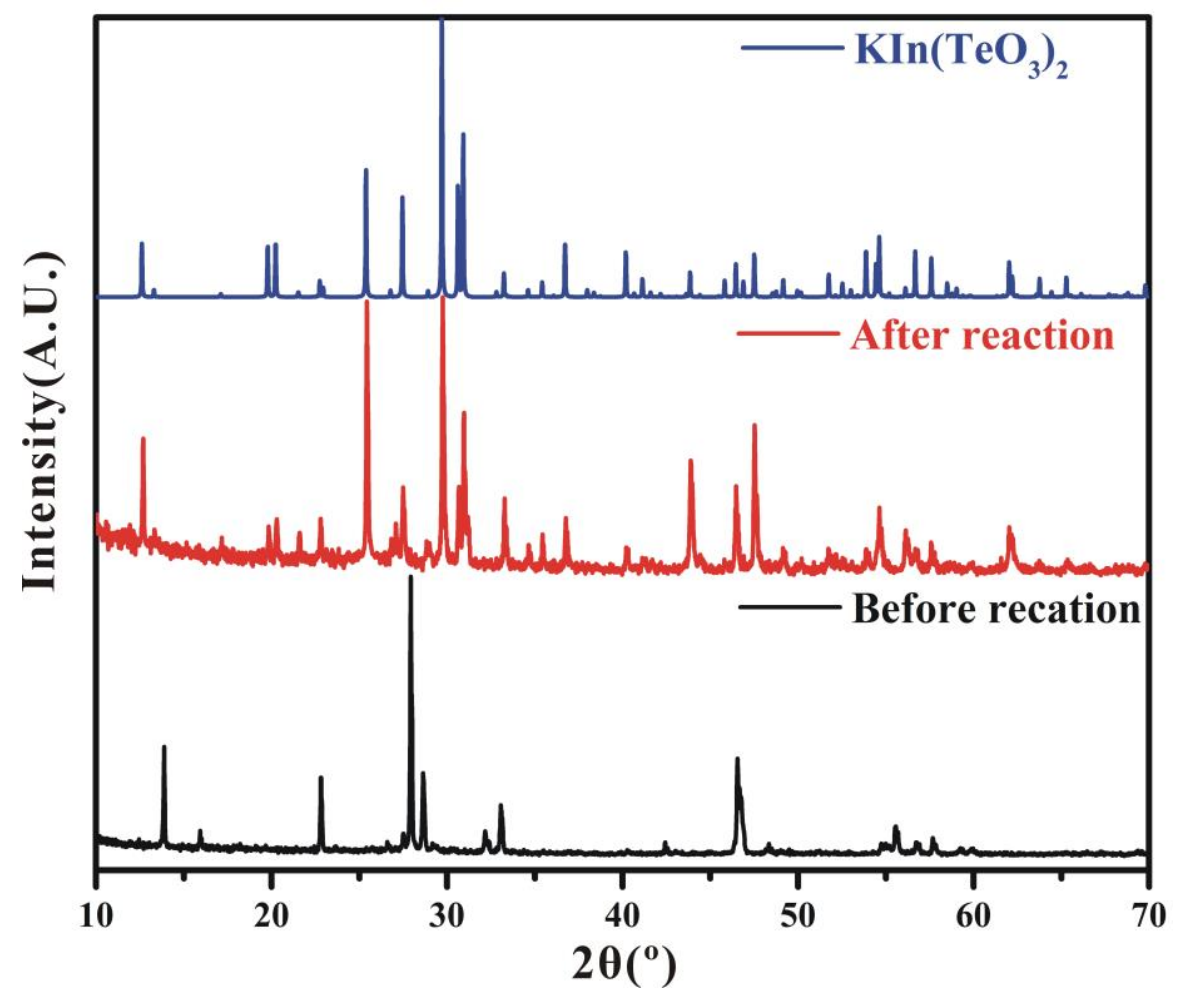




\section{REFERENCES}

(1) SAINT, version 8.27B, a program for area detector absorption correction. Siemens Analytical X-ray Instruments: Madison, WI, 2012.

(2) Blessing, R. H. An empirical correction for absorption anisotropy. Acta Crystallogr. 1995, A51, 33 38.

(3) Sheldrick, G. M. Crystal structure refinement with SHELXL. Acta Crystallogr. 2015, C71, 3-8. 